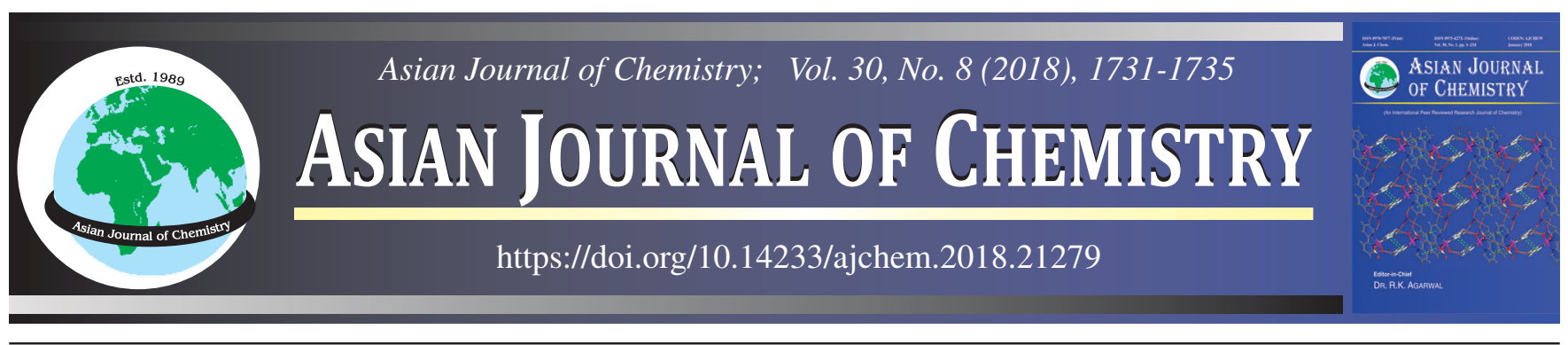

\title{
Gold Nanoparticles Supported on Carbon Derived from Solid Olive Waste for Epoxidation of Cyclooctene
}

\author{
Mosaed Alhumaimess
}

Department of Chemistry, College of Science, Jouf University, PO Box 2014, Sakaka, Kingdom of Saudi Arabia

Corresponding author: E-mail: mosaed@ju.edu.sa

The effect of using carbon black as a support for gold nanoparticles has been studied for the epoxidation of cyclooctene reaction. The carbon black supports were synthesized through the carbonization of solid olive waste at $300,400,500$ and $600{ }^{\circ} \mathrm{C}$. The sol-immobilization method was used to deposit gold nanoparticles onto carbon black supports. The catalytic activity of gold nanoparticles supported on the synthesized carbon was found to be dependent on the carbonization temperature of the supports. The gold nanoparticles deposited on carbon black synthesized at $600{ }^{\circ} \mathrm{C}$ was found to produce the best catalytic performance towards cyclooctene epoxidation. The high catalyst performance can be attributed to the gold nanoparticles and its dispersion on the support, which synthesized at $600{ }^{\circ} \mathrm{C}$, compared to the other supports. Some characterization techniques such as SEM, TEM and XRD were employed to investigate the synthesized carbon supports and their correspondent gold nanoparticles catalysts.

Keywords: Cyclooctene oxidation, Gold nanoparticles, Agricultural waste, Solid olive waste.

\section{INTRODUCTION}

Due to the impact of agricultural waste on the environment and the economy, many scientific studies have been carried out to find ways of transferring this waste into low-cost valuable products. Many types of agricultural waste have been reported in the literature concerning their potential transfer into beneficial products. Özçimen and Ersoy-Meriçboyu [1] used hazelnut shells and apricot stones to produce activated carbon as an adsorbent of copper(II) from aqueous waste streams. Soleimani and Kaghazchi [2] converted the hard shell of apricot stones into activated carbon and employed it to adsorb gold ions from wastewater. Vetiver roots were used by Altenor et al. [3] as raw materials for the production of activated carbon for the adsorption of methylene blue and phenol. Altaher and Dietrich [4] derived activated carbon from date pits to remove $o$ - and $p$-nitrophenols from wastewater. Olive stones were reported to be a source of activated carbon for the removal of dyes and heavy metals from wastewater as well as water purification from trace elements [5-10]. Moreno et al. [10] employed the activated carbon converted from olive stones as the sulfur host in Li-S batteries. Grapeseed agricultural waste has also been found to be an activated carbon adsorbent of copper from aqueous solutions [11]. Salman et al. [12] converted banana stalks into activated carbon for the purification of aqueous solutions from the insecticide carbofuran. The adsorption of
Pd(II) on the activated carbon synthesized from pinecones has also been reported [13]. Yuso et al. [14] adsorbed toluene from the aqueous solution on an activated carbon derived from almond shell. Poerschmann et al. [15] used the activated carbon derived from peach stones as a support for $\mathrm{Cu}$ and $\mathrm{Co}$ catalysts for methanol conversion reactions.

Other agricultural waste, such as bamboo dust, groundnut shells, rice husks and straw, corncobs, durian shells, sugars, wheat bran, walnut shells and hazelnut shells, have also been used as activated carbon sources for water treatment and environmental clean-up [16-18]. As illustrated above, almost all studies have focused on the production of activated carbon from agricultural waste, as it is an effective absorbent in many environmental fields. To my best of knowledge, there are no studies into converting agricultural waste into carbon black (not activated) due to the lack of its surface properties as an absorbent. Therefore, in this work, since Aljouf province is well known for its olive agriculture and olive oil production in Saudi Arabia, which has led to the abundance of olive waste. In this study, olive waste was collected and converted into carbon black and used as a support for gold nanoparticle catalysts for the epoxidation of cyclooctene. The importance of this work comes from using a local low-cost carbon source as a support for nano-catalysts, in addition to the disposability of solid olive waste. The aim is to create a link between agricultural waste and nanotechnology, so that it can be used in industrial chemical 
reactions. The conversion of carbon black from solid olive waste has been carried out using the physical method at high temperatures.

\section{EXPERIMENTAL}

Carbonization of solid olive waste: Olive solid waste was collected from an olive oil factory in Aljouf province in Saudi Arabia. Prior to carbonization, the olive solid waste sample ( $25 \mathrm{~g}$ ) was washed thoroughly with water, filtered and dried in an oven at $80^{\circ} \mathrm{C}$ for $8 \mathrm{~h}$. The carbon was obtained by the calcination of the washed olive stone waste in nitrogen (flow rate $=10 \mathrm{~mL} / \mathrm{min}$ ) using a furnace tube at different temperatures: $300,400,500$ and $600{ }^{\circ} \mathrm{C}$ for $2 \mathrm{~h}$ and these were denoted C300, C400, C500 and C600 respectively. The resultant carbonized samples were ground for $10 \mathrm{~min}$.

Synthesis of the gold supported catalysts: The sol-immobilization method was employed to deposit gold nanoparticles on the synthesized carbon materials (1\% Au). Typically, 0.062 $\mathrm{M}$ of $\mathrm{AuCl}_{3}$ solution (equivalent to $10 \mathrm{mg}$ of $\mathrm{Au}$ ) was added to distilled water $(400 \mathrm{~mL})$ while performing vigorous stirring. A fresh solution of poly(vinyl alcohol) (PVA) (1\% wt, MW = $10000,80 \%$ hydrolyzed) was added and stirred vigorously for $15 \mathrm{~min}(\mathrm{PVA} /$ gold $=1.2 \mathrm{w} / \mathrm{w})$. A fresh solution of sodium borohydride $(0.1 \mathrm{M})$ was then added to generate a gold sol. Following $30 \mathrm{~min}$ of stirring, the sol formed was immobilized through the addition of the synthesized carbon materials synthesized from olive waste $(0.99 \mathrm{~g})$ and acidified to $\mathrm{pH} 1$ by $\mathrm{H}_{2} \mathrm{SO}_{4}$ under and stirred for $1 \mathrm{~h}$. The solid catalyst was filtered, washed with distilled water (2 L) and dried at $100{ }^{\circ} \mathrm{C}$ for $24 \mathrm{~h}$. The catalysts were denoted $1 \% \mathrm{Au} / \mathrm{C} 300,1 \% \mathrm{Au} / \mathrm{C} 400$, $1 \% \mathrm{Au} / \mathrm{C} 500$ and $1 \% \mathrm{Au} / \mathrm{C} 600$ (300-600 refers to the carbonization temperature).

Epoxidation of cyclooctene: The catalysts were evaluated for the epoxidation of cyclooctene using a $50 \mathrm{~mL}$ round bottom flask fitted with a condenser. Typically, cyclooctene $(5 \mathrm{~mL})$ was stirred at $80{ }^{\circ} \mathrm{C}$ under atmospheric pressure, followed by the radical initiator (TBHP, $0.1 \mathrm{~mL}, 70 \%$ in $\mathrm{H}_{2} \mathrm{O}$ ) and the supported $1 \%$ Au catalyst $(60 \mathrm{mg}$ ) under solvent-free conditions for $24 \mathrm{~h}$. After the completion of the reaction, sample products were analyzed using gas chromatography (Varian star CP-3800) with a CP-wax 52 column and a flame ionization detector. Analyzing $\mathrm{CO}_{2}$ as a possible by-product by using this reactor set-up was unattainable. However, Hughes et al. [19] stated that the formation of $\mathrm{CO}_{2}$ is minimal.

Catalyst reuse: Proper amount of the fresh catalyst was stirred with cyclooctene under the reaction conditions. The catalyst was recovered, washed with acetone and dried for $24 \mathrm{~h}$ at $110{ }^{\circ} \mathrm{C}$. For reuse experiment, $0.12 \mathrm{~g}$ of the recovered catalyst was reused in a standard cyclooctene reaction.

Characterization: Powder X-ray diffraction (XRD) was determined using a PANalyticalX'Pert Pro with a CuK X-ray source operated at $40 \mathrm{kV}$ and $40 \mathrm{~mA}$ fitted with an X'Celerator detector. The BET surface area was determined by nitrogen adsorption at $-196{ }^{\circ} \mathrm{C}$ using a Quadrasorbevo ${ }^{\mathrm{TM}}$. Scanning electron microscopy (SEM) analyses were carried out on a Carl Zeiss EVO-40 SEM equipped with a backscatter detector and an Oxford Instruments Si-Li energy dispersive X-ray detector. Transmission electron microscopy (TEM) analysis was performed using a $200 \mathrm{kV}$ JEOL 2000FX electron microscope equipped with a thermionic LaB6 source.

\section{RESULTS AND DISCUSSION}

Carbonization of the solid olive waste and synthesis of Au/carbon: Four carbon black supports were synthesized from solid olive waste using a physical method at high temperatures. Fig. 1 illustrates the powder X-ray diffraction for these supports and a commercial carbon black (Johnson Matthey) as a reference. The main peaks for the carbon black material can be found at $2 \theta=26$ for (002) plane, $2 \theta=43$ for (100) plane and $2 \theta=53$ for $(004)$ plane $[19,20]$. However, only the main peak at $2 \theta=23$ appeared in sample C300, indicating the uncompleted carbonaization of this sample (Fig. 1b). The main peaks at $2 \theta=$ 26 and 43 were shown in sample C400 (Fig. 1c). All of the main peaks were found in samples C500 and C600, which confirms the completed carbonization of these two samples.

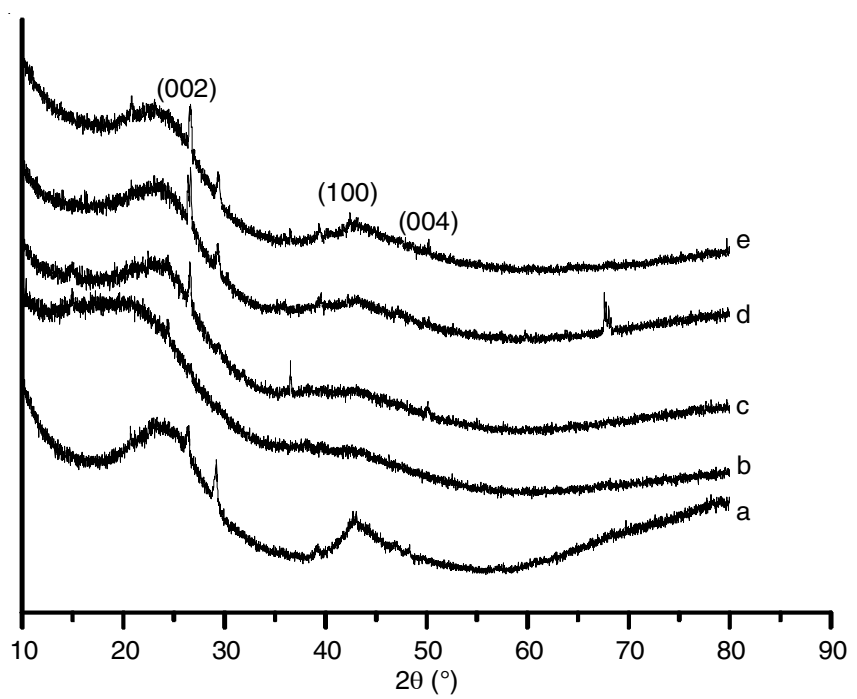

Fig. 1. XRD patterns of carbonized olive waste: (a) commercial, (b) C300, (c) C400, (d) C500 and (e) C600

The morphology of the synthesized supports was analyzed using scanning electron microscopy (Fig. 2). Although there was no difference in the morphology, the particle size of the
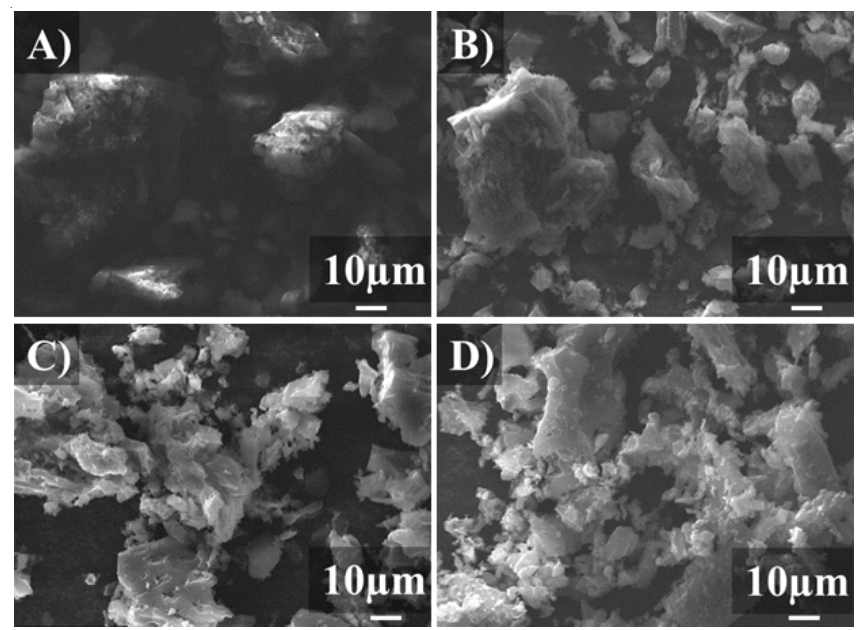

Fig. 2. SEM images of carbonized olive waste: (A) C300, (B) C400, (C) C500 and (D) C600 
synthesized carbon supports differed considerably according to the carbonization temperature. As the carbonization temperature increased, the particle size decreased, due to the ease of grinding for the supports synthesized at high temperatures, which led to smaller particles. As shown in Fig. 2, the majority of the particles for supports $\mathrm{C} 300$ and $\mathrm{C} 400$ were big particles with minor small particles. Nevertheless, for supports C500 and C600 there were some big particles but the majority were small and homogeneous. Surface area was investigated for all supports synthesized and the results are shown in Table-1. It is clear that the surface area of the supports was directly proportional to the calcination temperature and $\mathrm{C} 600$ had the highest surface area $\left(32.0 \mathrm{~m}^{2} / \mathrm{g}\right)$.

TABLE-1

SURFACE AREA AND AVERAGE PORE SIZE FOR CARBON SUPPORTS SYNTHESIZED AT DIFFERENT TEMPERATURES

\begin{tabular}{cc}
\hline Sample & BET surface area $\left(\mathrm{m}^{2} / \mathrm{g}\right)$ \\
\hline C300 & 8.5 \\
C400 & 9.0 \\
C500 & 25.5 \\
C600 & 32.0 \\
\hline
\end{tabular}

For further analysis of the support effect on the on the gold nanoparticles distribution, all synthesized carbon supports were characterized using transmission electron microscopy. Fig. 3 illustrates the gold particle size distribution and the mean size for all gold/synthesized carbon catalysts. The mean size of each carbon support was calculated using the following equation (based on 300 gold particle):

$$
\overline{\mathrm{D}}=\frac{\Sigma \mathrm{n}_{\mathrm{i}} \mathrm{d}_{\mathrm{i}}}{\Sigma \mathrm{n}_{\mathrm{i}}}
$$

It is clear that the gold nanoparticles supported on C300 and C400 have the largest gold nanoparticles, wider particle size distribution and largest Au mean size. On the contrary, the Au supported on the carbon synthesized at higher temperatures, C500 and C600, have narrower Au particle size distribution and smaller Au mean size. The catalyst Au/C600 in particular, has the smallest mean size of 0.9 , along with narrow particle size distribution.

Epoxidation of cyclooctene using $\mathrm{Au} / \mathrm{C}$ : The epoxidation reaction of cyclooctene was carried out under atmospheric pressure using solvent free conditions. Fig. 4 shows the chemical reaction equation for cyclooctene epoxidation. Bawaked et al. $[21,22]$ investigated the reaction conditions for cyclooctene epoxidation using gold catalysts, such as reaction temperature and the type of radical initiator and its concentration and support. The reaction conditions used in this work were the optimized conditions that Bawaked et al. discovered in their work $[21,22]$. Table- 2 shows the catalytic performance of the $1 \%$ Au supported on the synthesized carbon black supports towards epoxidation of cyclooctene. It is clear that the catalyst activity increased with the carbonization temperature of the supports. The catalyst $1 \% \mathrm{Au} / \mathrm{C} 600$ exhibited the best catalytic performance, with $9.0 \%$ conversion and $89.0 \%$ selectivity to the desirable product (epoxide). The catalytic activity can be attributed to the gold particle size and particle size distribution as well as the surface area of the supports, as illustrated in Fig.
3 and Table-1. It is well known that gold's particle size and its distribution have a great effect on the activity of gold catalysts [23-26]. The catalysts $1 \% \mathrm{Au} / \mathrm{C} 300$ and $1 \% \mathrm{Au} / \mathrm{C} 400$ exhibited lower activity due to the larger gold particles and their dispersion on the supports (Fig. 3). The enhancement in activity was greater for the catalyst $1 \% \mathrm{Au} / \mathrm{C} 500$, with $6.0 \%$ conversion, although it has the same selectivity to epoxy as catalyst $1 \% \mathrm{Au} /$ C400. This can be explained by the good gold dispersion on the support in addition to the smaller gold mean size for catalyst $1 \% \mathrm{Au} / \mathrm{C} 500$. The catalyst $1 \% \mathrm{Au} / \mathrm{C} 600$ exhibited the best conversion and selectivity, at $9.0 \%$ and $89.0 \%$ respectively. This was due to the smallest mean size of the gold particles in addition to the support high surface area. The supports used in this study differ in their particle size (Fig. 2) and it is known that this can have a great effect on the gold particle size and its distribution and therefore on the catalyst's activity [23-26]. Bawaked et al. [21,22] investigated many supports, namely graphite, activated carbon, $\mathrm{TiO}_{2}, \mathrm{SiO}_{2}, \mathrm{Al}_{2} \mathrm{O}_{3}$ and $\mathrm{SiC}$ and under the same reaction conditions used in this study, the best conversion they produced was $7.7 \%$ with 81.5 selectivity to the epoxy product for $1 \% \mathrm{Au} / \mathrm{graphite}$. This study shows that the carbon black support derived from solid olive waste can be an excellent alternative natural support as well as having a positive environmental impact.

\begin{tabular}{|c|c|c|c|c|}
\hline \multicolumn{5}{|c|}{$\begin{array}{c}\text { TABLE-2 } \\
\text { EPOXIDATION OF CYCLOOCTAENE } \\
\text { OVER THE } 1 \% \text { Au/CARBON CATALYSTS }\end{array}$} \\
\hline \multirow[b]{2}{*}{ Catalyst } & \multirow[b]{2}{*}{$\begin{array}{c}\text { Conversion } \\
(\%)\end{array}$} & \multicolumn{3}{|c|}{ Selectivity $(\%)$} \\
\hline & & \begin{tabular}{l}
0 \\
\multirow{J}{0}{} \\
0 \\
0 \\
0 \\
0
\end{tabular} & 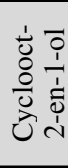 & 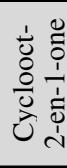 \\
\hline TBHP without catalyst & 0.8 & 68.0 & 19.1 & 12.9 \\
\hline C600 (blank) & 1.9 & 75.0 & 14.8 & 10.2 \\
\hline $1 \% \mathrm{Au} / \mathrm{C} 300$ & 2.3 & 83.5 & 11.4 & 5.4 \\
\hline $1 \% \mathrm{Au} / \mathrm{C} 400$ & 3.9 & 86.6 & 8.2 & 5.2 \\
\hline $1 \% \mathrm{Au} / \mathrm{C} 500$ & 6.0 & 86.9 & 8.2 & 4.9 \\
\hline $1 \% \mathrm{Au} / \mathrm{C} 600$ & 9.0 & 89.0 & 7.0 & 4.0 \\
\hline
\end{tabular}

Catalyst reusability: The reusability of heterogeneous catalysts is an important factors for economy and green chemistry. The catalysts $1 \% \mathrm{Au} / \mathrm{C} 600$ was chosen for reuse experiments (Table-3) due to the high performance it exhibited among all catalysts. After the reaction of cyclooctene, the catalyst was collected by centrifuge, washed with acetone three times and then dried at $110^{\circ} \mathrm{C}$ for $24 \mathrm{~h}$. The catalyst is reusable until the second reuse as the conversion decreased by $14 \%$. The deactivation of the catalyst was observed after the third reuse.

\section{Conclusion}

It has been shown that using solid olive waste as a source for carbon black supports for gold nanoparticles produces catalysts, which exhibit higher activity than some commercial supports for epoxidation of cyclooctene. Moreover, utilizing agricultural waste for catalytic applications would have a highly positive environmental impact. 

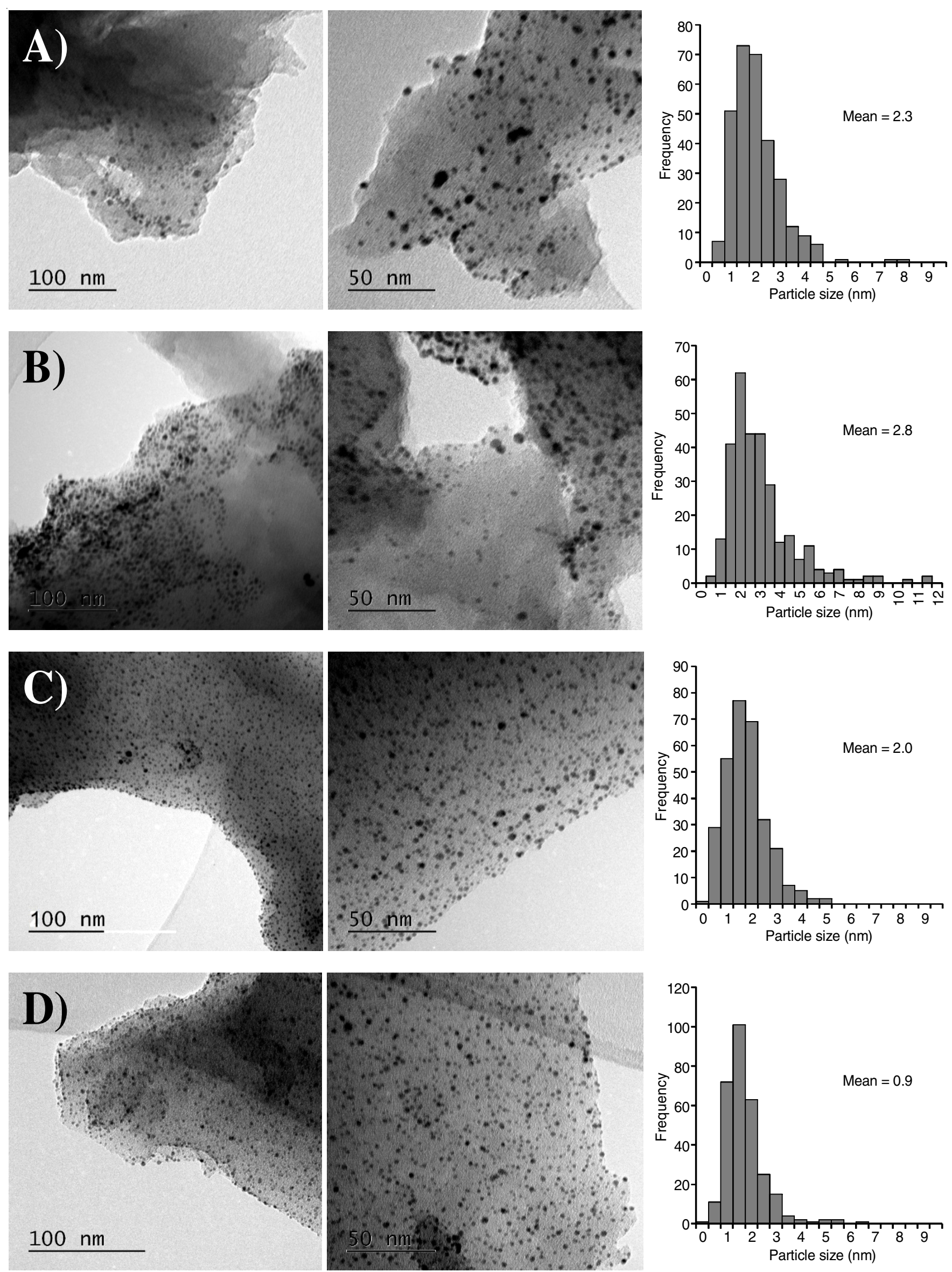

Fig. 3. TEM micrographs and the corresponding Au particle size distributions for (A) Au/C300, (B) Au/C400, (C) Au/C500 and (D) Au/ C600 


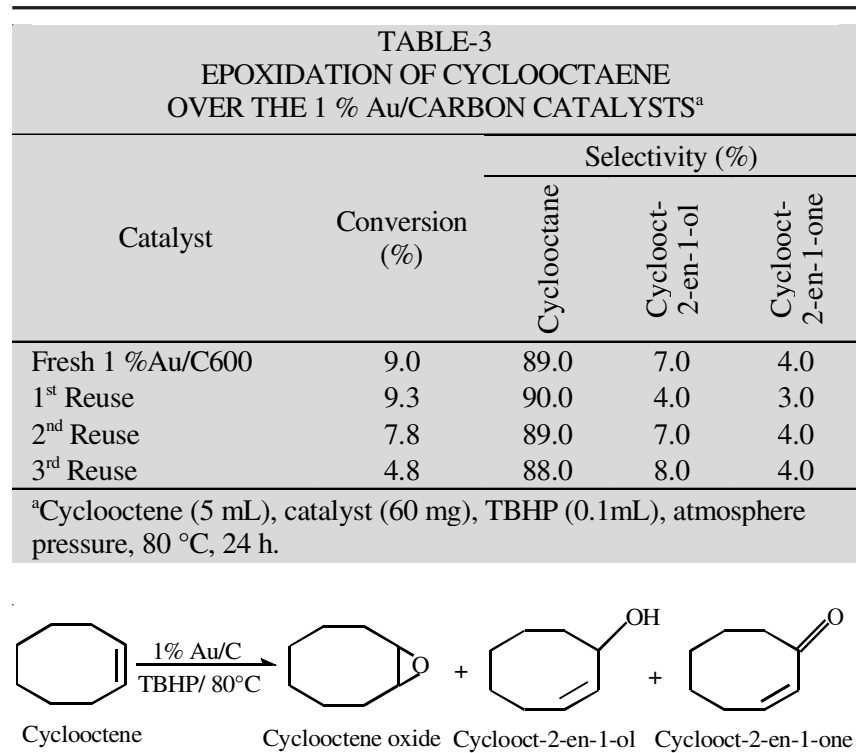

Fig. 4. Epoxidation of cyclooctene using $1 \% \mathrm{Au} / \mathrm{C}$ and TBHP

\section{ACKNOWLEDGEMENTS}

The author thanks Jouf University for the financial support provided for this study (Project number 431/37).

\section{REFERENCES}

1. D. Özcimen and A. Ersoy-Meriçboyu, Adsorpt. Sci. Technol., 28, 327 (2010);

https://doi.org/10.1260/0263-6174.28.4.327.

2. M. Soleimani and T. Kaghazchi, Bioresour. Technol., 99, 5374 (2008); https://doi.org/10.1016/j.biortech.2007.11.021.

3. S. Altenor, B. Carene, E. Emmanuel, J. Lambert, J.-J. Ehrhardt and S. Gaspard, J. Hazard. Mater., 165, 1029 (2009); https://doi.org/10.1016/j.jhazmat.2008.10.133.

4. H. Altaher and A.M. Dietrich, Water Sci. Technol., 69, 31 (2014); https://doi.org/10.2166/wst.2013.522.

5. S. Najar-Souissi, A. Ouederni and A. Retal, J. Environ. Sci. (China), 17, 998 (2005)

6. T.M. Alslaibi, I. Abustan, M.A. Ahmad and A.A. Foul, Environ. Prog. Sustain. Energy, 33, 1074 (2014); https://doi.org/10.1002/ep.11877.

7. N. Petrov, T. Budinova, M. Razvigorova, J. Parra and P. Galiatsatou, Biomass Bioenergy, 32, 1303 (2008); https://doi.org/10.1016/j.biombioe.2008.03.009.

8. R. Baccar, J. Bouzid, M. Feki and A. Montiel, J. Hazard. Mater., 162, 1522 (2009);

https://doi.org/10.1016/j.jhazmat.2008.06.041.
9. T. Bohli, A. Ouederni, N. Fiol and I. Villaescusa, Int. J. Chem. Eng. Appl., 3, 232 (2012); https://doi.org/10.7763/IJCEA.2012.V3.192.

10. N. Moreno, A. Caballero, L. Hernán and J. Morales, Carbon, 70, 241 (2014); https://doi.org/10.1016/j.carbon.2014.01.002.

11. D. Özcimen and A. Ersoy-Mericboyu, J. Hazard. Mater., 168, 1118 (2009); https://doi.org/10.1016/j.jhazmat.2009.02.148.

12. J.M. Salman and B.H. Hameed, J. Hazard. Mater., 176, 814 (2010); https://doi.org/10.1016/j.jhazmat.2009.11.107.

13. M. Momcilovic, M. Purenovic, A. Bojic, A. Zarubica and M. Randelovic, Desalination, 276, 53 (2011); https://doi.org/10.1016/j.desal.2011.03.013.

14. A.M. de Yuso, M.T. Izquierdo, B. Rubio and P.J.M. Carrott, Adsorption, 19, 1137 (2013); https://doi.org/10.1007/s10450-013-9540-5.

15. J. Poerschmann, I. Baskyr, B. Weiner, R. Koehler, H. Wedwitschka and F.-D. Kopinke, Bioresour. Technol., 133, 581 (2013); https://doi.org/10.1016/j.biortech.2013.01.154.

16. M. Rafatullah, O. Sulaiman, R. Hashim and A. Ahmad, J. Hazard. Mater, 177, 70 (2010); https://doi.org/10.1016/j.jhazmat.2009.12.047.

17. T. Alslaibi, I. Abustan, M.A. Ahmad and A.A. Foul, J. Chem. Technol. Biotechnol., 88, 1183 (2013); https://doi.org/10.1002/jctb.4028.

18. J.M. Dias, M.C.M. Alvim-Ferraz, M.F. Almeida, J. Rivera-Utrilla and M. Sánchez-Polo, J. Environ. Manage., 85, 833 (2007); https://doi.org/10.1016/j.jenvman.2007.07.031.

19. M.D. Hughes, Y.-J. Xu, P. Jenkins, P. McMorn, P. Landon, D.I. Enache, A.F. Carley, G.A. Attard, G.J. Hutchings, F. King, E.H. Stitt, P. Johnston, K. Griffin and C.J. Kiely, Nature, 437, 1132 (2005); https://doi.org/10.1038/nature04190.

20. F.C. Tai, C. Wei, S.H. Chang and W.S. Chen, J. Raman Spectrosc., 41, 933 (2010); https://doi.org/10.1002/jrs.2532.

21. S. Bawaked, N.F. Dummer, N. Dimitratos, D. Bethell, Q. He, C.J. Kiely and G.J. Hutchings, Green Chem., 11, 1037 (2009); https://doi.org/10.1039/b823286p.

22. S. Bawaked, N.F. Dummer, D. Bethell, D.W. Knight and G.J. Hutchings, Green Chem., 13, 127 (2011); https://doi.org/10.1039/C0GC00550A.

23. J. Huang, W.L. Dai and K. Fan, J. Catal., 266, 228 (2009); https://doi.org/10.1016/j.jcat.2009.06.011.

24. X. Zhang, H. Wang and B.Q. Xu, J. Phys. Chem. B, 109, 9678 (2005); https://doi.org/10.1021/jp050645r.

25. K. Ho and K. Yeung, Gold Bull., 40, 15 (2007); https://doi.org/10.1007/BF03215288.

26. W. Yan, B. Chen, S.M. Mahurin, V. Schwartz, D.R. Mullins, A.R. Lupini, S.J. Pennycook, S. Dai and S.H. Overbury, J. Phys. Chem. B, 109, 10676 (2005); https://doi.org/10.1021/jp0440910. 